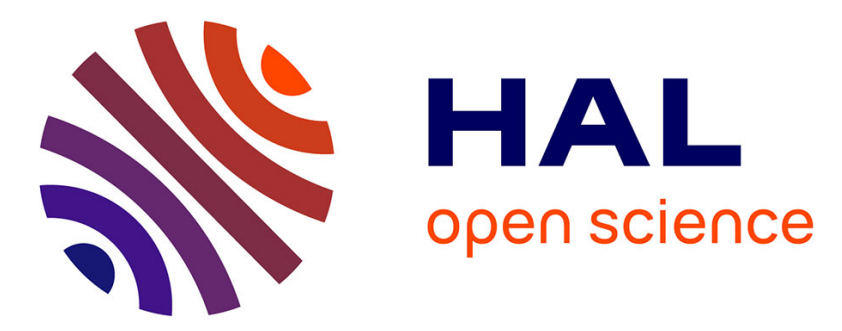

\title{
Cell-penetrating and cell-targeting peptides in drug delivery.
}

Eric Vivès, Julien Schmidt, André Pèlegrin

\section{To cite this version:}

Eric Vivès, Julien Schmidt, André Pèlegrin. Cell-penetrating and cell-targeting peptides in drug delivery.. Biochimica et Biophysica Acta - Molecular Cell Research, 2008, 1786 (2), pp.126-38. 10.1016/j.bbcan.2008.03.001 . inserm-00281555

\section{HAL Id: inserm-00281555 https://www.hal.inserm.fr/inserm-00281555}

Submitted on 23 May 2008

HAL is a multi-disciplinary open access archive for the deposit and dissemination of scientific research documents, whether they are published or not. The documents may come from teaching and research institutions in France or abroad, or from public or private research centers.
L'archive ouverte pluridisciplinaire HAL, est destinée au dépôt et à la diffusion de documents scientifiques de niveau recherche, publiés ou non, émanant des établissements d'enseignement et de recherche français ou étrangers, des laboratoires publics ou privés. 


\title{
Cell Penetrating and Cell Targeting Peptides in Drug Delivery (revised version)
}

Eric Vivès*, Julien Schmidt and André Pèlegrin.

${ }^{1}$ IRCM, Institut de Recherche en Cancérologie de Montpellier, Montpellier, F-34298, France ; INSERM, U896, Montpellier, F-34298, France ; Université Montpellier1, Montpellier, F34298, France ; CRLC Val d'Aurelle Paul Lamarque, Montpellier, F-34298, France

* Telephone : (33)-467-61-25-18 ; fax : (33)-467-61-37-87 ; e-mail: evives@ valdorel.fnclcc.fr

Keywords: cancer, cell-penetrating peptide, cell-targeting peptide, cell delivery, drug.

\begin{abstract}
During the last decade, the potential of peptides for drug delivery into cells has been highlighted by the discovery of several cell-penetrating peptides (CPPs). CPPs are very efficient in delivering various molecules into cells. However, except in some specific cases, their lack of cell specificity remains the major drawback for their clinical development. At the same time, various peptides with specific binding activity for a given cell line (cell-targeting peptides) have also been reported in the literature. One of the goals of the next years will be to optimize the tissue and cell delivery of therapeutic molecules by means of peptides which combine both targeting and internalization advantages. In this review, we describe the main strategies that are currently in use or likely to be employed in the near future to associate both targeting and delivery properties.
\end{abstract}

\section{Contents}

1. Cell-Penetrating Peptides (CPPs) 
1.1. CPPs and cell entry

1.2. Problems and limitations of CPPs for drug delivery in vivo.

1.3. Toxicity of cationic CPPs.

2. Local CPP-mediated delivery

2.1. Some ways to home CPPs

2.1.1. Exploiting the peritumoral acidic $\mathrm{pH}$

2.1.2. Exploiting matrix metalloproteases

2.1.3. Exploiting the biological state of targeted cells

2.2. CPP-loaded devices and local release

2.2.1. Thermal sensitive polymers

2.2.2. Ultrasound sensitive particles

3. Cell-Targeting Peptides (CTPs)

3.1. Identification of CTPs

3.1.1. Structure-activity relationship of ligands

3.1.2. Phage display

3.1.3. Chemical strategies (One Bead One Compound, ligand mimetic...)

3.2. Improving CTPs

3.2.1. The RGD peptide: a "scholar study"

3.2.2. Cyclization

3.2.3. Multimerization

4. CTPs first, then CPPs?

5. Conclusions and future directions

References

1. Cell Penetrating Peptides (CPPs) 
The efficient passage of drugs through the plasma membrane remains a major hurdle for drug delivery. Good cell uptake often requires the administration of high quantities of drugs in order to obtain the expected intracellular biological effect. Therefore, improving the translocation process across the plasma membrane will significantly reduce the quantity of drug to be administered, and the side effects on healthy tissues that are currently observed in most of the cases.

In the nineties, several proteins have been shown to translocate spontaneously through the plasma membrane when incubated in the extracellular medium. In particular, two of these molecules have been extensively studied in order to define the structural or sequence elements needed for the translocation: the Tat protein from the HIV-1 virus $[1,2]$ and the Drosophila melanogaster Antennapedia homeodomain [3]. A study on the structure-activity relationship was carried out on these two small proteins of 101 and 60 amino acids, respectively, and the minimal domain needed for translocation was defined [4-6]. This corresponds to short sequences of 10 to 16 amino acids, thus opening the way to the chemical synthesis of different mutants and analogues that are called "Cell Penetrating Peptides" (CPPs) or "Protein Transduction Domains" (PTDs). However, since "non-natural" peptide sequences that are quite different from the conventional PTD have also been used as cell translocating units for drug delivery $[7,8]$, we prefer the acronym CPP for such family of peptides.

Both Tat and Antennapedia peptides contain several basic amino acids. The native Tat peptide is composed of several cationic amino acids, including 6 arginine and 2 lysine residues. Starting from this native composition, the potential of arginine homopeptides to promote cellular uptake has been rapidly realized $[9,10]$, as it was demonstrated that the arginine-rich peptide is more efficient than the other cationic (i.e. poly-lysine, poly-histidine or polyornithine) homopolymers [11]. The strong impact of arginine residues has been described by Futaki's group [10, 12] and further investigated by Rothbard and Wender, and others, who 
performed a systematic replacement of arginine residues with alanine residues $[11,13]$. Such substitutions induced a strong reduction of peptide uptake that was directly correlated with the number of substituted arginines. Therefore, Rothbard et al. proposed that a bidentate hydrogen-bonding interaction between the guanidinium group of arginine residues and phosphate groups in the membrane [14] is implicated in the mechanism of translocation.

Surprisingly, the role of cationic amino acids in the Antennapedia peptide has not been so extensively studied, whereas the influence of the tryptophane residues has been comprehensively investigated [4]. In line with this, a peptide made of arginine and tryptophane residues only and showing an efficient translocating potency has been recently designed [15].

Altogether, the studies on Tat and Antennapedia peptides represent more than $75 \%$ of the published work on CPPs (for reviews, see [16] and [17]), and in the last two years this percentage even increased with several publications being reported weekly in the literature. The Antennapedia peptide has been also marketed as "Penetratin". Under this commercial version, an activated group sensitive to nucleophilic attack by a sulfhydryl function conveniently allows the spontaneous formation of a disulfide bridge between any cargo molecule and "Penetratin". At the time of writing this review however, only 172 results appeared in Medline for the keyword "Penetratin". Most of them are fundamental studies mainly about the entry mechanism of CPPs or the biological evaluation of a coupled drug, whereas only a little number concerns clinical applications. It is noteworthy to consider that a stable covalent linkage has to be formed between CPP and cargo to allow translocation, at least for Tat, Antennapedia, or poly-Arg peptides, although a couple of publications also reported a surprising efficacy upon simple mixing with the cargo entities [18, 19]. Similarly, another CPP, Pep-1, which has been marketed as "Chariot" [20], can induce internalization of a cargo molecule just by being mixed with it [21]. A very little number of references on 
"Chariot" can be however found in the literature despite its apparent ease of use. As for other CPPs, the debate about the mechanism of entry of "Chariot" is still ongoing. Although being described initially as energy-independent, further works have proposed different mechanisms, such as the association of helices [22] or the formation of discrete nano-particles [23]. Controversies about the formation of pores through the membrane have also been reported $[24,25]$.

\subsection{CPPs and cell entry}

As mentioned in the previous section, the entry mechanism of CPPs into cells is still a matter of some debate. Historically, two hypotheses were put forward to explain how these peptides could possibly deliver various kinds of molecules, and also much larger macromolecular structures, into the cell (for a review [16]). It was first proposed that CPPs, especially Tat and Antennapedia, but also others such as poly-Arg [10, 26], Transportan [27], MPG [28] or Pep1 [20], could pass through the plasma membrane via an energy-independent pathway. Some suggestions have been put forward to explain the translocation of these peptides, such as the formation of micromicelles at the membrane [5], or direct translocation through the lipid bilayer [29, 30]. If conceivable for small CPPs, these models can not explain the passage through the plasma membrane of CPPs-cargoes of very important size $[31,32]$. The hypothesis of a direct translocation through the plasma membrane became less popular when the entry mechanism for the Tat and the poly-arginine CPPs had to be re-evaluated following evidences of fixation artifacts during the preparation for samples for microscopic observation [33]. Indeed, fixation has been described to interfere with the sub-cellular localization of constructs with a high content in cationic residues, such as histones and the VP22 protein [34]. This redistribution upon fixation has been clearly demonstrated using fusion proteins made of Antennapedia, poly-Arg, or Tat peptides [35]. As a consequence, the majority of the 
new microscopic studies on CPP-cargoes localization have been conducted on living cells. As a result, during these last few years, numerous new works about the mechanism of entry of CPPs appeared in the literature, but the conclusions we can draw from these very elegant works could be summarized by: "the more we learn, the less we know". As a matter of fact, there has been a profusion of publications highlighting one or another entry route, sometimes with some obvious discrepancies. CPP-mediated transport has been shown, so far, to mainly follow a cellular endocytosis-mediated uptake [36-38].

According to this mechanism, CPPs, particularly those with a high content in cationic residues, are first simply adsorbed at the cell surface thanks to the numerous anionic moieties, such as heparan sulfate, sialic or phospholipidic acid [39-41]. Then CPP-mediated transport has been reported to happen through different endocytosis routes [33]: via caveolae [42], macropinocytosis [43, 44], through a clathrin-dependent pathway [45], via a cholesteroldependent clathrin-mediated pathway [46] or in the trans-Golgi network [47]. Some publications have provided convincing arguments against one or the other of these cellular pathways despite the use of rather similar experimental models. It has been suggested that these controversies might be due to the use of different peptide concentrations as they can trigger different endocytotic pathways $[38,48]$. Higher CPP concentration $(>10 \mu \mathrm{M})$ could also lead to an energy-independent internalization [38, 49]. A molecular mechanism for a direct translocation of the Tat peptide through the plasma membrane has been also recently described [50]. In conclusion, more work is needed to highlight unambiguously the precise mechanism(s) of entry of these peptides.

In addition, since no cellular pathway appears absolutely predominant or more convincing than another one, most of these pathways could be involved depending on yet unknown events such as the concentration, the net charge, the hydrophobicity or other physico-chemical parameters of the CPPs. In several studies, initial ionic interactions at the cell membrane 
surface have been however shown to be key determinants for the uptake of all the cationic CPPs since the peptide entry could be strongly reduced by competition with polyanionic compounds [51-54] or by stringent cell washes with solutions at acidic $\mathrm{pH}$ [55].

Moreover, the way of entry into the cell could also be influenced by the nature of the cargo, the type of CPP, the cell line and the conditions of incubation (for example, the CPP concentration as shown above). There is still a major need to compare different CPP-mediated delivery systems in the same cell model. Attempts have been made recently to compare the effects of the cargo as well, but none of these studies could define precise rules that might explain all the observed discrepancies $[49,56]$.

Despite all the controversies about the route of entry, some consensual features are now privileged, at least for the Tat peptide and other multi-cationic CPPs. First, the entry mechanism implies the use of pathways that are sensitive to lysosomotrophic agents, such as chloroquine and sucrose $[57,58]$. Moreover, the efficacy of the cell uptake is improved by coincubation of Tat with another peptide derived from the hemagglutinin protein which has membrane fusogenic properties [59], or by the use of photochemical internalization mediated by a membrane soluble photosensitizer [60].

Since the endosomial pathway is likely to be involved in the cellular delivery of Tatconjugated molecules whatever the initial route, a strong enzymatic degradation within this compartment and a poor cytoplasmic release of intact molecules from this compartment are expected, thus leading to a global weak transfer into the cytoplasm. Therefore, increasing the escape rate from the endosome could be a strategy to improve the intracellular delivery of CPP-attached molecules. How could this be done? One possibility could be to increase the hydrophobicity of CPPs to favor the destabilization of the endosomal membrane. To this aim, lipid moieties have been coupled to molecules to be delivered inside the cells. For example, a cholesterol unit has been attached to a free terminus of an oligonucleotide hairpin, thus 
enhancing its cellular delivery in comparison to conventional transfection methods [61]. In another study, cholesterol-derivatized oligonucleotides also showed a rapid binding and cytosolic partition in cells [62]. Closer to the CPP context, cell delivery improvement has been also observed upon stearylation of an octa-arginine peptide [63] or following the introduction of a proline amino acid derivative with a higher hydrophobicity into a prolinerich CPP [64]. In most of these studies, except for the last one, the derivatization of peptides with lipids was performed at the N-terminal end as it allowed easy coupling of the lipid by conventional amide bond formation directly on the peptidyl-resin after completion of the peptide sequence. We are currently developing an approach to insert lipophilic groups anywhere within the CPP sequence to increase the destabilization of cellular or endosomial membranes.

\subsection{Problems and limitations of CPPs for drug delivery in vivo.}

Although highly efficient in mediating the in vitro cell uptake of different molecules into most cell lines, the in vivo use of CPPs appears much more complicated mainly because of a complete lack of cell specificity. Indeed, CPPs, and the therapeutic molecules attached to them, are dispersed almost all over the body independently of the way of administration (intravenous, IV, or intraperitoneal, IP). Such spreading has been highlighted by a seminal work that also underlines the CPP potential as a therapeutic approach [65]. After IP injection, the short Tat cell-penetrating sequence [6] fused to $\beta$-galactosidase was found in the lung, liver, kidney and other tissues, and, more surprisingly, in the brain, demonstrating that this fusion protein could cross also the blood brain barrier [65]. To our knowledge, the brain translocation of a Tat-fusion protein was confirmed in a single example with Bcl-xL, a wellcharacterized death-suppressing molecule of the Bcl-2 family, also following IP injection [66]. An other CPP related to the protegrins family has been also shown to pass across the 
blood brain barrier [67]. However, no study has been published so far to explain precisely how CPPs and their cargoes could cross this highly selective membrane. More importantly, no complete bio-distribution has been provided for such CPP-mediated in vivo transports.

Much effort has been put into improving the cell uptake of antibodies coupled to various CPPs since the tumor-targeting efficiency of most anticancer antibodies is severely limited by their poor penetration into the tumor mass [68]. As already discussed in a previous review [69], the coupling of cell specific antibodies to CPPs did increase their cellular internalization in vitro as expected [70]. However, it also reduced significantly their selectivity in vivo since non-targeted tissues took up the chimeric construct through non-specific internalization mediated by the CPP. This study revealed that the higher the number of CPP copies grafted on a cell-specific monoclonal antibody (Mab), the lower was the specificity of the Mab for the native cell. Significant localization and retention of CPP-Mab fragments in non-targeted tissues in vivo have been confirmed more recently by Jain et al., especially with a high peptide to antibody ratio [19]. In this study, the cell-penetrating "driving force" predominated over the specific antigen binding of the Mab fragments. Similarly, Niesner et al. observed a complete loss of in vivo cellular specificity when a tumor-targeting $\mathrm{scFv}$ fragment was coupled to the Tat peptide [68].

CPP-mediated delivery of an antibody raised against p21, an intracellular target inducing G1S phase cell cycle arrest, has also been reported [71]. Compared to the uncoupled antibody, Tat increased the cellular accumulation of radio-labeled anti-p21 of about 10 folds, and the in vivo distribution study demonstrated that the Tat-conjugated anti-p21 Mab was more concentrated in tumors than the un-conjugated Mab [71]. However, accumulation of the Tat modified Mab in other tissues was also observed. In conclusion, the tumor to normal tissue ratio did not improve upon conjugation of the anti-p21 Mab with the Tat peptide. 
Stein et al. conjugated a longer version of the Tat peptide spanning along residues 37 to 72 of the HIV-1 Tat protein to a Fab fragment of anti-tetanus toxin antibodies either by thioether or disulfide linkage [72]. They demonstrated that only the disulfide conjugates effectively neutralized the toxin. Surprisingly, the disulfide conjugate also showed a higher nuclear accumulation compared to the thioether conjugate [72]. One would have expected the opposite result since the intracellular reducing environment should be strong enough to cause the disulfide bridge reduction as shown in a previous study with a CPP-peptide conjugate [73]. Therefore, as a nuclear localization sequence (NLS) is present within the Tat peptide sequence [74], it is difficult to understand why the Fab fragment enters more efficiently the nucleus with a reducible linker than with a stable one. We already discussed extensively in a previous review [40] the features of reducible and stable links in CPP-morpholino-nucleic acid chimeras [75] and also in that case argued for an intracellular reduction of the chimeras in the cellular environment.

Moreover, Kameyama et al. showed some important differences in the body distribution, retention and metabolic fate of the conjugates depending on the type of CPP used (Tat, Antennapedia and Rev peptides coupled to the same Fab fragment) [76]. In another study, Tat or Antennapedia peptides were co-administrated with $\operatorname{sc}(\mathrm{Fv})_{2}$ fragments [19]. In such a situation, there was no stable link between the CPPs and the $\operatorname{sc}(\mathrm{Fv})_{2}$ fragment. However, a higher tumor retention was observed with the Antennapedia peptide and, to a lower extent, with the Tat CPP than with the $\operatorname{sc}(\mathrm{Fv})_{2}$ fragment alone. However, the Tat peptide used in this study lacked one arginine residue [19]. Therefore, the lower tumor retention observed with Tat in this work should be reconsidered as the replacement of just a single cationic residue in Tat can greatly decrease its cell uptake $[11,13]$. In another work a mixture of CPPs (Antennapaedia or Tat peptides) and cargo molecules were used to improve internalization of 
replication-deficient viruses for the therapeutic gene delivery, both in vitro and in vivo [18], but unfortunately, no bio-distribution study was performed.

To conclude this section and despite the lack of a clear understanding of how CPPs deliver cargo molecules into the cell, there are evidences that CPPs induce a strong non-specific binding by sticking any molecule attached to them to non-targeted cells, leading to a dramatic loss of very "precious" material. Therefore, this issue is probably one of the major drawbacks for the use of these peptides as in vivo delivery vehicles if alternative strategies are not developed to promote cell-specific delivery.

\subsection{Toxicity of cationic CPPs.}

Because of their highly cationic nature, one could fear that some CPPs could be as toxic as other cationic polymers such as poly-L-Lysine or poly-ethylene imine (PEI) (for a review, [77]). Moreover the cationic Tat peptide has been shown to mediate some neurotoxicity (for a review, see [78] and $[79,80])$. Therefore several groups evaluated their in vitro and in vivo cellular toxicity. When the minimal membrane-translocating Tat domain was discovered [6], no toxicity has been found in very extreme conditions on HeLa cells ( $24 \mathrm{~h}$ incubation at 100 micromolar concentration). This absence of toxicity has been also shown in other studies. For example, Toro et al. confirmed that the short Tat peptide was not toxic for lymphocytes at dose up to $300 \mu \mathrm{M}$ [81]. Using different cationic peptides (namely Tat, Antp, Rev and VP22), no toxicity was observed in Hela or Jurkat cells with up to $20-30 \mu \mathrm{M}$ concentrations [82]. SiRNA transfected in vivo with a poly-Arginine peptide did not induce any cellular toxicity at a ratio of negative/positive charges of 40 [83]. Frequent injections in mice of a fusion protein corrected the metabolic disorder and immune defects with no apparent toxicity [81]. Incubation of primary or immortalized human keratocytes with the Antennapepdia or Tat peptide resulted in no evidence of toxicity with dosage up to $200 \mu \mathrm{M}$ and $400 \mu \mathrm{M}$, 
respectively. Similar results were obtained with a human trabecular meshwork cell line, primary human foreskin fibroblasts, Vero, and HeLa cells. In the same work, toxicity was evaluated in vivo by applying peptides to the cornea 4 times daily for 7 days. At concentrations 1000 times the IC50 values, the Antennapedia peptide showed no toxicity, whereas Tat caused some mild eyelid swelling [84]. Park et al. described the equivalent cell translocation potency of a short protamine derivative rich in arginine residues which was equivalent to that of the Tat peptide combined with the absence of toxicity [85]. Cardozo et al. showed that concentrations of up to $100 \mu \mathrm{M}$ of Tat(48-57) were essentially harmless in all cells tested, whereas Antp(43-58) was significantly more toxic [86]. In addition, it is noteworthy that peptide concentrations used in toxicity tests are in their very large majority far above the concentrations used for delivering various drugs into cells (which range from 1 to $10 \mu \mathrm{M})$.

\section{Local CPP-mediated delivery}

The apparent in vivo "spreading" of CPP-coupled molecules could be circumvented if the chimerical constructs could be applied directly on the targeted cells, or at least in their close vicinity. Local application of CPPs could be compared to an in vitro experiment. This has been performed, for instance, with an arginine homopolymer to vectorize cyclosporine A into the skin [87]. In this study, crossing of the stratum corneum and diffusion into the epidermis was observed, although fixation artifacts were not considered at that time. This chimera entered a phase II clinical trial in 2003 for the treatment of psoriasis under the commercial name of PsorBan®. However, despite an efficient uptake of the chimera, the release of the free drug was not rapid enough to compete with clearance (P.A. Wender, personal communication). Local delivery of drugs through a CPP has been attempted also in 
the vitreous body and in the sub-retinal space of the eye following intraocular injection of CPPs [88]. In such a situation, any diffusion of the CPPs is obviously strongly reduced. Intracoronary injections of a Tat-delta protein kinase C inhibitor chimera (KAI-9803) have also been used for the treatment of acute myocardial infarction [89]. In addition to local intracoronary administration, KAI-9803 just commenced in March 2007 an intravenous phase 1 clinical study.

Moreover, delivery to the lungs of siRNAs bound to CPPs has been also described [90]. Indeed, topical delivery to lungs is facilitated by either intranasal, intratracheal or aerosol administration (for a recent review [91]). In the study by Moschos and colleagues, a siRNA designed to turn off the expression on an intracellular protein (the p38 MAP kinase) was conjugated through a disulfide bridge to Antennapedia or Tat peptides. A 30 to $45 \%$ knockdown of the corresponding RNA was recorded at $6 \mathrm{~h}$ post-administration. However, and rather unexpectedly, higher doses of the chimera did not induce a stronger response. It is also noteworthy to point out that Tat and Antennapedia-coupled siRNAs induce different cellular responses, reflecting apparently a different intracellular fate of these two conjugates [90], as already mentioned in another study [92].

\subsection{Some ways to home CPPs}

Some particular situations have been exploited to bypass the absence of cell specificity of CPPs and to design molecular systems to improve targeting. These are based on the physiological or biological features of the targeted organ or cell type, such as its microenvironment or its enzymatic activity. In all cases, the CPP domain is first somehow hidden prior reaching the targeted area to avoid unspecific uptake. After reaching its target, CPP is then fully exposed to promote an efficient internalization. Cancer cells are very often 
targeted for a therapeutic purpose, and their metabolism, which is different from that of normal cells, can be used to improve the delivery specificity.

\subsubsection{Exploiting matrix metalloproteases}

In 2004, the first targeting system which uses an "activable" CPP was described (Figure 1A) [93]. It exploited the ability of a specific CPP (the arginine homopolymer) to interact intra-molecularly with a polyanionic counterpart through ionic interactions. Both ionic parts of this construct were linked together via a cleavable matrix metalloprotease (MMP) sequence, forming a hairpin. When the construct was introduced in the blood stream (at a concentration of around $6 \mu \mathrm{M}$ ), no cleavage occurred due to the insufficient level of circulating MMPs. Thanks to the neutralization of the cationic charges by the anionic counterparts, the cationic CPP could not interact anymore with the anionic charges of the cells of the blood vessels and, therefore, unspecific binding was avoided. Around a tumor, MMPs concentration increases significantly because they are secreted by tumor cells. Thus, the linker could be cleaved, the ionic parts of the chimera dissociated, and CPP ability to bind to the surrounding cells was restored. In this way, a preferential uptake by the tumor cells was made possible. Since a payload molecule is covalently attached to the CPP, this strategy is an alternative mean to concentrate CPP-transported molecules into tumor cells. In other words, this CPP-based molecular construct promotes an indirect, but more specific delivery system in vivo [93].

\subsubsection{Exploiting the peritumoral acidic $\mathrm{pH}$}

More recently, ionic interactions between CPPs and their anionic counterparts have been exploited to temporally hide the cellular "sticky opportunism" of cationic CPPs during their transport towards the tumor site [94]. This delivery system consists of two components: 
a conventional hydrophobic core made of a polymer into which any chemotherapeutic molecule can be incorporated, and a peripheral hydrophilic layer composed of polyethylene glycol and the Tat peptide. An anionic and ultra-sensitive di-block copolymer is then complexed to the cationic Tat. Such ionic interactions are expected to shield the cationic charges during delivery up to when the slightly acidic microenvironment of the tumor triggers the protonation of the anionic moiety. This induces the ionic dissociation and the subsequent exposure of the Tat peptide sequence, allowing the preferential internalization of the drugloaded polymer into the surrounding tumor cells [94] (Figure 1B). This strategy has been pursued using the very $\mathrm{pH}$-sensitive sulfonamide (PSD) group [95]. The PSD compound is fully protonated at $\mathrm{pH} 7.4$ (the $\mathrm{pH}$ in the blood stream) and becomes neutral at $\mathrm{pH} 6.8$ [96]. The peritumoral $\mathrm{pH}$ has been evaluated to be about $6.9+/-0.14$ at the tumor-host interface, rising from 7.10 to 7.15 at only 200 micrometers away from the tumor [97]. Indeed, this $\mathrm{pH}$ gradient strongly reduces the "effective volume" where the Tat peptide could be freed from its pro-drug structure. The main advantage is again that the Tat peptide is active only in close proximity of the tumor area. On the other hand, the main inconvenience is that the volume where the pro-drug becomes effective is very small as compared to the whole circulation. Therefore, the pro-drug peptide needs to reach rapidly the peritumoral area to fulfill its therapeutic effect prior to its renal and/or hepatic elimination. Further studies are indeed required to provide all the kinetic parameters of this interesting strategy.

Similarly, Kale et al. obtained an enhanced in vivo transfection of DNA using pH-sensitive Tat-modified pegylated (PEG) liposomes (Figure 1D) [98]. Basically, a number of PEG chains were attached to the liposome surface that contained also some Tat peptides of much smaller size. The steric hindrances created by the PEG coat were expected to shield the surface-attached Tat peptides, therefore preventing again the non-specific liposome/cell interactions. Since these long PEG chains were coupled to the liposome surface through a pH- 
sensitive hydrazone linker, cleavage of the linker could occur only in the acidic environment of the tumor [98]. In experiments performed in tumor-bearing mice, the liposomes were administered directly intra-tumorally, and allowed to obtain at least a three times more efficient transfection than with the corresponding $\mathrm{pH}$-insensitive system. Whether the intratumoral injection is required to improve the efficacy of this approach is currently unknown.

The exploitation of the acidic $\mathrm{pH}$ has been also described for a peptide derived from the HA2 glycopolypeptide of the influenza virus hemagglutinin [99]. The aim was to improve cytoplasmic delivery of cargo molecules performed with CPPs. In this case, the lyzosome acidification, down to $5 \mathrm{pH}$ units, induced a conformational change of the HA2 derivedpeptide, leading to a structural change and exposure of a fusion property. More recently, a Tat-HA chimeric peptide has been used by Dowdy's group to improve the escape of the TatCre recombinase fusion construct co-incubated in the experiment [59]. The Tat peptide from the Tat-HA chimera probably caused a higher membrane adsorption of the HA peptide itself, thus increasing its cellular uptake followed by lyzosomal destabilization. Subsequently, the improvement of the cytoplasmic escape of the HA-Cre fusion construct could be recorded [59]. The problem with this strategy is that there is no possibility to target a specific cell line as the endocytotic pathway is ubiquitous.

\subsubsection{Exploiting the biological state of targeted cells}

Another approach is to take advantage exclusively of the internal biological status of the targeted cell, as caused by an infection, or of a metabolic change induced by a pathological disorder. For instance, one can imagine that a toxic molecule, coupled to a CPP as a harmless pro-drug, could be activated only once inside a specific type of cells. Such a strategy has been elegantly achieved by Dowdy's group in 1999 (Figure 1C) [100]. In this study, they fused the Tat peptide to a caspase-3 protein precursor that could be activated only 
upon cleavage by the HIV protease. This chimerical construct is processed into its active form only by the HIV protease that is exclusively present in HIV-infected cells. This results in caspase-3 induced apoptosis of these cells. This construct was shown to transduce efficiently about $100 \%$ of cells and remained indeed fully inactive in healthy cells. Despite these very promising results a well-controlled in vivo experiment in humanized T cell SCID mice is required to definitively validate this approach (S.F. Dowdy, personal communication).

The same group also used the Tat peptide fused to the p27 tumor suppressor to evaluate the effect of its transduction on tumor proliferation in vitro and in vivo [101]. Cell cycle arrest of tumor cells was obtained in culture and an inhibition of the tumor growth was observed in mouse models. These encouraging data have, however, to be considered with the "pharmacist's eye" for two reasons: first, the experimental model had peritoneal tumors and the chimerical molecule was injected directly into the peritoneal cavity. Therefore, this strategy can be considered as a local therapy, thus strongly reducing the risks of a large spreading of the Tat-fusion construct in the circulation. Second, two injections of $300 \mu \mathrm{g}$ of fusion protein during four days were necessary to obtain the expected biological activity. Since the Tat-p27 chimerical molecule has a molecular weight of $25 \mathrm{kDa}$, this dose corresponds, for one single injection, to a molar excess of more than 140 folds compared to Trastuzumab®, a monoclonal antibody used in therapy in current standard treatments against some cancers. The need of such an important dose could be the direct consequence of the low quantity of Tat-derived construct which enters effectively the cell. Indeed, ongoing work in our laboratory indicates that less than one percent of the extracellular Tat peptide enters effectively the cell (Vivès et al.; in preparation). However, the use of CPPs to mediate the anti-tumoral response is very attractive and it has been reported in the literature. GarciaEcheverria and colleagues designed a short peptide to disrupt the interaction between p53 and hDM2 [102] in order to restore p53 activity in tumor cells. It was then coupled to a CPP (the 
Antennapedia peptide), but apparently, the biological evaluation in vivo was not further developed, despite preliminary in vitro tests showing that the chimera did not impair the activity of the interfering peptide [103]. Other groups have obtained in vivo responses following mainly IP, but also with IV or local administration of CPP-peptides at doses ranging from some milligrams to some fractions of microgram per $\mathrm{kg}$ (for a recent review [104]). However, although IP injection is commonly used in mouse models, IV or subcutaneous injections would be preferred for a clinical development.

\subsection{CPP-loaded devices and local release}

As already discussed, cationic CPPs have the undesired characteristic of entering most of the cells they get in contact with. Therefore, once injected in the body, most of the peptides and indeed the drug attached to them will be internalized in the "wrong" cells. As described in the previous chapters, efforts to overcome these limitations have led to the generation of new chimerical molecules. These molecules are often complex, certainly rather difficult to synthesize and/or fully characterize, and to market. To circumvent these problems, it is also conceivable to design cell-penetrating systems showing a certain form of specificity, by simply allowing a CPP-loaded device to diffuse very close to the environment of the tissues to be targeted. This is indeed viable only in the case of a localized pathology, such as solid tumors, or of directly accessible organs. It may be indeed feasible for the treatment of various cutaneous pathologies, and possibly lung diseases, and eventually for reaching the ocular cavity or the digestive tract, for instance. Moreover, several drug delivery sustained release systems, including gel matrix, nanocapsules, liposomal structures, to name but a few, have been described in the literature (for recent reviews in this field, see volume 59, issues 4 and 5 of the Advanced Drug Delivery Reviews (2007)). Some of them could trigger the release of the encapsulated drug specifically in the region requiring the therapy, however the 
problem of the rapid and efficient internalization of these drugs into the targeted cells would remain. This could be solved by attaching a CPP to the therapeutic molecule. To our knowledge, such a strategy combining a local delivery device and a CPP internalization system still remains very marginal, although some examples of its application have been described.

\subsubsection{Thermal sensitive polymers}

There are some alternative means to efficiently direct drugs into a specific cell type with CPPs. For instance, a chemotherapeutic CPP-coupled doxorubicin conjugate has been included in a macromolecular carrier made of an Elastin-like polypeptide (ELP) [105]. This carrier is thermal sensitive with a phase transition occurring between $39^{\circ} \mathrm{C}$ and $42^{\circ} \mathrm{C}[105$, 106]. This temperature range is sufficiently above the normal body temperature to prevent unwanted systemic aggregation. Therefore, following external and focused hyperthermia, which can be induced with different devices such as pulsed-high intensity focused ultrasounds (HIFU) [107], the Tat-drug conjugate can be released in the tumor environment and preferentially taken up by the tumor cells. Additionally, a Gly-Phe-Leu-Gly tetrapeptide spacer (sequence GFLG) was joined to the Tat peptide and the doxorubicin molecule. This sequence corresponds to the target sequence of a protease belonging to the cathepsin family [108]. Since the CPP is internalized mainly by endocytosis [33], the lysosomal proteases are expected to cleave and release active drug moieties within the cell. In this study, a 20-fold enhancement of the effect of the drug was recorded when aggregation of ELP was induced by localized hyperthermia [105].

More recently, Curley and colleagues have used a thermal sensitive device made of carbon nanotubes [109]. By injecting these nanotubes into cancer cells and then zapping them with radio-frequency waves, they created an important increase in temperature that led to the death 
of cancer cells. Radio-frequency waves can be used in this case because of the particular electronic properties of carbon nanotubes and they are more attractive than the near-infrared laser heating method used in others strategies. Moreover, carbon nanotubes could be derivatized with various proteins to improve their specificity [110]. Indeed, it might be feasible to link these nanotubes to CPPs, to improve their cellular uptake, or to targetingpeptides to concentrate them at the tumor site.

\subsubsection{Ultrasound sensitive particles}

Ultrasounds can also be used to deliver drugs in a very precise body area. They are currently evaluated for two main applications. The first one relies on focused sonication to deliver drugs or genes into the tissue where the sonication is applied as ultrasounds can reversibly increase the micro-permeation (sonoporation) of the membrane, thus inducing cellular transfer of the extracellular medium $[111,112]$. Indeed if the blood stream is loaded with the drug to be transfected into the cells, a more potent delivery of the molecule can be expected locally in the area of sonication. However, it is worth to mention that the sonication effects do not last long. In other words, this strategy mimics an in vitro transfection performed in vivo, thus leading to a higher degree of drug delivery in the cells within the treated area. Sonication has been shown to improve the delivery efficacy of a cytotoxic agent, leading to a significant reduction of the injected dose [113]. However, if applied to small drugs, a rapid clearance from the blood stream can be expected, which will reduce the time window of the sonication effects.

Therefore, to limit this problem, some attempts have been made to deliver in the blood stream stable molecular structures that are exclusively sensitive to ultrasounds [114]. This strategy allows the entrapment of various drugs prior sonication, inducing their release only in the targeted environment [114]. Moreover, the concomitant use of drugs conjugated to CPPs and 
sonication should further improve the local cellular delivery. However, only hydrophobic molecules, such as doxorubicin for instance [115], can be successfully inserted in ultrasound sensitive structures. Since most of the CPPs are rather hydrophilic because of their high cationic content, their inclusion in theses structures is compromised unless their coupling to doxorubicin reduces significantly their hydrophilicity, or more extended hydrophobization of the CPPs is performed. Additional lipophilic group(s) could also favor the escape of CPPs from the endosomes and, subsequently, the overall efficacy of this "targeted" delivery strategy. This approach is currently evaluated in our group.

\section{Cell Targeting Peptides (CTPs)}

Beside CPPs, different peptides composed of a few amino acids (from 3 to 10) that are cell specific and are internalized by endocytosis are emerging in the literature (Table 2). Some of these peptides are called cell targeting peptides (CTPs) and have been already used in various therapeutic assays [116]. CTPs show high specificity and strong affinity for a given targeted cell line upon interactions with a receptor that is exclusively over-expressed by these cells. The most extensively studied among them is probably the RGD peptide ([117] and [118] for recent reviews), the first tumor-homing peptide discovered [119]. In the next sections we will describe most of the work done to improve the specificity and the affinity of this peptide since we think that this can well illustrate the issues related to CTPs.

\subsection{Identification of CTPs}

Several monoclonal antibodies that target cell surface receptors, such as the anti-CD20 antibody Rituximab, have been approved for cancer treatment (for a review [120])._However, the large size of the antibody $(160 \mathrm{kDa})$, the high cost of its production and characterization as well as its relatively nonspecific binding to the reticulo-endothelial system represent major 
drawbacks when cytotoxic drugs or radionuclides are coupled to the antibody. On the other hand, binding to the reticulo-endothelial system can be considered as an advantage when the antibody is naked as it can induce an immunological response which can destroy tumor cells. It is expected that binding of macrophages to the Fc fragment of these antibodies will also favor the immune response. Therefore, because of their easier preparation and their good affinity or specificity, short peptides or peptido-mimetics are attractive alternative targeting agents for either cancer imaging or therapy. Various peptides that target specifically one given cell line have been identified using different techniques aimed at defining the shortest peptide with the highest specificity and affinity (Table 1).

\subsubsection{Structure-activity relationship of ligands}

The most intuitive way of designing a specific binding peptide for a given receptor is to start either from the structural data or from the structure-activity relationship study of the molecular interactions between a circulating protein and its cellular receptor. However, structural data are not always available and structure-activity relationship studies seldom advance to a linear well-defined sequence which could be directly used as a receptor-specific binding peptide, mainly because the tertiary structure scaffolding frequently hides the ligandreceptor interactions. Nevertheless, some short peptide sequences have been defined by these conventional methods $[121,122]$.

For instance, the erbB2 receptor has been targeted with an erbB2 receptor-binding heptapeptide (see Table 1) attached to the pro-apoptotic alpha-tocopheryl succinate ( $\alpha$-TOS) [123]. The chimera between the $\alpha$-TOS moiety and the receptor-binding hepta-peptide reduced breast carcinomas expressing high levels of erbB2 in transgenic mice. Another hepta-peptide binding to Neuropilin-1 (NRP), a vascular endothelial growth factor (VEGF) receptor, has been evaluated in vitro [124] and more recently in vivo [125]. The peptide used against 
circulating VEGF was initially identified by phage display (see next section), and then a linear 20-mer peptide was further studied by X-rays crystallography to improve its binding properties to VEGF. It was shown that this peptide was unstructured in solution but adopted a largely extended conformation upon binding to VEGF [126]. This observation confirms the dynamic process leading to high affinity binding. The initial interaction favors the next one, and so on, until the peptide secondary structure is finally changed. X-rays data also indicate that, upon binding, residues 3 to 8 of this peptide form a beta-strand structure pairing with the beta 6-strand of VEGF via six hydrogen bonds, which leads to a rather strong interaction of the peptide with VEGF. However, the parent peptide could not be shortened to less than 14 residues without dramatically reducing the binding efficiency. To our knowledge, this 14 merversion of the VEGF binding peptide has not yet been evaluated in vivo.

\subsubsection{Phage display}

Several peptides that target specifically cancer cells or tumor blood vessel endothelial cells have been identified using two techniques based on a combinatorial approach (i.e., phage display and One Bead One Compound). The phage-display technique relies on the combinatorial generation of short peptide sequences inserted in the extracellular protein of a filamentous phage [127]. Upon interactions of the phage with a specific extracellular receptor of a given cell type, the phage is amplified following cell infection. Limiting dilutions of the transfected suspension are then made, and one single phage type can be isolated after several rounds of selection. Subsequently, the "active" combinatorial sequence is identified by sequencing. The phage display technique allows the identification of peptide sequences ranging from 8 to 12 amino acids. Once characterized, the peptide itself is evaluated for its ability to bind with high specificity and strong affinity to the specific receptor of the targeted cell. 
In terms of synthesis, the sequences highlighted by phage display are interesting and their production is not difficult. Indeed, nowadays, peptide chemistry is easy and quite cheap for peptides up to 15 amino acids, and they can be synthesized with rather good yields. Although some longer peptides have also reached the drug market (the best known among them is probably the 36 amino acid-long T20 or Fuseon, used for antiviral treatment of HIV (for a review [128])), the synthesis of such large peptides is more complicated and requires more expensive production techniques. Peptide length could also be a concern when considering the structural aspects of the peptide-ligand interactions. Except in some very specific cases, peptides of less than 15 amino acids are poorly structured. Therefore, their affinity or their specificity might be somehow reduced when extracted from the displaying protein-phage. However, by inserting cysteine residues at both ends of the identified sequence by genetic engineering, it is possible to apply a structural constraint through the formation of a disulfide bridge, leading to a cyclic peptide within the phage protein $[129,130]$. Such cyclization often improves the affinity of the peptide towards the target receptor in comparison to the linear form (see below). The main inconvenience of the phage display technique as an abundant source of new cell-specific ligands is that, because of its biological origin, only natural Lamino acids can be inserted in the peptide sequence. Therefore, ligands with higher affinity can be missed out. However, once a native sequence has been identified, it is also possible to carry out a structure-activity relationship study on analogues harboring non-natural synthons. This is probably the reason why the second technique was developed about a decade ago [131].

\subsubsection{Chemical strategies (One Bead One Compound, ligand mimetics...)}

The chemical generation of libraries, which include both $\mathrm{D}$ - or non-natural amino acids, has been recently developed, offering the possibility of discovering new ligands with 
either higher affinity or better specificity for a given cell receptor. This synthetic technique is based on the combinatorial synthesis of one compound on one single solid bead, thus generating random peptides, each with its own unique amino acid sequence on the same bead. Hence, it has been defined as the "one-bead one-compound" (OBOC) strategy [132], and has led to the discovery of a large number of specific ligands (for a recent review [133]). Once the library has been assembled, various cell lines can be grown in the presence of the beads. A cell type growing on one bead clearly indicates the interaction of a membrane receptor with the peptide assembled on that particular bead. The sequence of the peptide attached on the bead is then determined by sequencing. Competition experiments between the peptide attached on the bead and the soluble peptide allow to confirm the sequence specificity and to measure various parameters.

The main advantage of this technique is that non-natural amino acids can be inserted within the sequence. For instance, a peptido-mimetic called LLP2A showed a very high affinity for the $\alpha 4 \beta 1$ integrin receptor of activated T- and B-lymphomas with an IC50 of 2pM [134]. The main benefit of such non-natural ligands is their high stability against proteases. LLP2A showed an extreme resistance to proteases with no sign of degradation after 18 days of incubation in human plasma at $37^{\circ} \mathrm{C}$. Indeed, this is a major advantage when developing a targeting peptide. The question of the blood clearance of such small molecules has not yet been completely resolved.

\subsection{Improving CTPs}

The affinity and/or avidity of CTPs for their receptor can be improved in different ways. In general, cyclization and multimerization of the peptide have been used to boost the interaction with the target receptor. These aspects are developed in the following sections through one of the best studied examples, the RGD tri-peptide that presents a specific 
interaction with the integrin receptors. We think that the wealth of research on this peptide is likely to be transferable to any other short peptide showing specific affinity for a given cell receptor.

\subsubsection{The RGD peptide: a "scholar study"}

The $\alpha v \beta 3$ integrin receptor plays a role in angiogenesis of solid tumors, cell migration, invasion and also metastatic activity (for a review [135]) and it expression depends on the type and stage of the tumor. Therefore, it became rapidly a target of choice for cancer treatment. In the early 80's, the Arg-Gly-Asp (RGD) sequence, which is present in various circulating proteins, was shown to be responsible for the binding to the $\alpha v \beta 3$ receptor either on its own or included in a penta-peptide. Then, much work was focused on the definition of the requirements needed to produce a ligand with very strong affinity/selectivity towards $\alpha v \beta 3$. This led to the development of a molecule, Cilengitide, which is now in phase II study. Researches are still trying to find more specific ligands to reduce the currently used pharmacologic doses. As explained in a very recent and exhaustive review about the design and chemical synthesis of integrin ligands [118], small changes within the natural sequence of these molecules could deeply improve their activity profiles. For instance, in the c-RGDfV peptide, where $\mathrm{f}$ stands for a D-amino acid, each amino acid was replaced by its $\alpha-\mathrm{N}$ methylated form [136]. Depending on the structure-activity refinement of the $\mathrm{N}$-methylation position for instance, the specific binding (IC50) varied from $10^{-5} \mathrm{M}$ for the $\mathrm{c}(\mathrm{RGD}(\mathrm{NMe}) \mathrm{fV}$ ) to $10^{-8} \mathrm{M}$ for the $\mathrm{c}(\mathrm{RGDf}(\mathrm{NMe}) \mathrm{V})$, which represents a gain of more than 1000 folds [118]. This is also illustrated by the replacement of the aspartate (D) residue by glutamate (E) within the RGD peptide. The resulting RGE sequence has an additional methylene group and is used as a negative control peptide for monitoring integrin binding. Another peptide used as a negative control is RAD in which the alanine (A) residue replaces the glycine (G) of RGD. 


\subsubsection{Cyclization}

It is commonly admitted that the interaction between a peptide ligand and its receptor shows higher affinity when the peptide is under a constrained conformation rather than simply linear [137]. Moreover, resistance against proteases is also largely increased upon cyclization [138]. One of the nicest examples to illustrate these aspects is probably again the Arg-GlyAsp (RGD) tri-peptide. The linear RGD peptide recognizes its target receptor, and has been initially used as a targeting peptide [139]. However, this peptide is inserted in the turn localized at the extremity of a $\beta$-sheet within two of the natural ligands of the integrin receptor, fibronectin and vitronectin. The bend of such a turn involves 3 to 4 residues. Therefore, the RGD peptide was rapidly synthesized in a cyclized form in order to mimic its natural environment within the protein. One of the first "cyclization" was performed by bridging two cysteine side chains placed at the two extremities of the peptide [140, 141]. Around the same time, cyclization using chemical closure, mainly through the formation of an amide bond within the $\mathrm{N}$-ter $\alpha$-amine and the $\mathrm{C}$-ter $\alpha$-carboxyl functions, was also introduced [142]. Cyclo-peptides with five to six amino acid residues represent the best compromise between flexibility and reactivity to obtain cyclization with good yields. Other types of ring closure have been also performed through various chemical strategies, and peptido-mimetics have been inserted at the place of different native residues. This sometimes leads to molecules apparently far away from the native tri-peptide, in which the charge locations of the ionic side chains (Arg (R) and Asp (D)) have to be placed and oriented accordingly (for recent reviews, see $[118,143]$.$) .$

\subsubsection{Multimerization}


The affinity of a dimeric ligand for its receptor is usually higher than that of the corresponding monomeric molecule [144]. In most examples, the increased avidity is the mechanical result of a higher local concentration of ligands because of the direct linkage between two moieties. Since the binding of a ligand to its receptor is a dynamic event, if one molecule becomes detached from the receptor, it is statistically more likely to observe the instantaneous re-attachment of the second half of the dimer to the same receptor molecule. On the other hand, a dimeric ligand could also bind to two adjacent receptors, thus increasing the overall strength of the apparent affinity of the two receptors. It has to be pointed out that initial multimerization of targeting sequences have been made by repeating two or more adjacent recognition sequences [145] and this feature strengthens the hypothesis of a higher local concentration, since it appears unlikely that two adjacent receptors could bind to two sequences so closely linked along the same primary sequence. One might definitely solve this issue by modifying the length of the linker joining the two monomers. The crystal structure of the $\alpha v \beta 3$ receptor in its activated state allowed the observation that the $\alpha$ and $\beta$ sub-units assemble into an ovoid volume of $60 \AA$ to $90 \AA$ [146]. Since the $\alpha v \beta 3$ binding site is located in a central cleft between the two subunits, the minimum length of a linker between two ligands should be at least of $60 \AA$ to allow binding to two adjacent receptors. In most studies with cyclic divalent RGD peptides, the spacer length between the two ligands was much shorter than the length required for binding two contiguous receptors [147-149]. Moreover, in a recent study, a dimeric RGD with a spacer compatible in length with a putative attachment of the dimer to two adjacent receptors did not have a stronger affinity than a molecule with a shorter spacer length, or the monomer [150]. This study revealed also that dimers with intermediate length spacers (from 29A to 43A) provided the best cell uptake, thus indirectly confirming that binding to two neighbor receptors could not explain the better affinity. In some cases, homo-bivalent ligands can cross-link two adjacent receptors when bound through 
an optimal linker length which is correlated to the inter-receptor distance [151]. Moreover, the flexibility of the linker can also influence the kinetics of the binding as the presence of flexible PEG moieties within the linker significantly modifies the level of recognition [151]. This data stresses again the plethora of possible modifications within a single molecule.

With the aim to investigate the limit of multimerization, several study further evaluated the affinity of tetra- and octa-meric RGD structures [147, 152-154]. The monomeric c(RGDfV) peptide was grafted on a multi-branched core made of different functional groups. In most of the cases, the ligand exposing scaffold also carried a second type of functional group, able to link another molecular entity ranging from a radionuclide for tumor localization during diagnostic phase, to a drug to promote the specific killing of the targeted cells. For instance, Dumy et al. synthesized a planar cyclodecapeptide scaffold with a face harboring four RGD cyclopeptides, and the other one a fluorescein [154]. However, the ultimate goal of such a strategy is to deliver a cytotoxic molecule into cells which harbor $\alpha v \beta 3$ receptors and preliminary encouraging in vivo experiments have been very recently published $[155,156]$. Kessler's group evaluated the requirement of multimerization to improve the binding affinity of the monomeric RGD moiety [153]. To this aim they used a scaffold made of lysine moieties, that is known under the acronym of MAP (i.e., multiple antigen peptide) and was conceived in the 90's to expose several antigenic peptides in order to avoid their coupling to a carrier protein [157]. RGD peptides were attached to the MAP structure via PEG chains.

In conclusion, the use of multimeric RGD structures improves the apparent affinity, or more precisely the avidity of the ligand for the integrin receptor compared to the monomeric ligand. The majority of the reported studies limited the investigation to 8 RGD moieties at most, and in general tetra- di- and monomers were used. The efficacy was $4>2>1$ RGD peptide [147], but it has been also described a $2>4>1$ RGD peptide efficiency [158]. These discrepancies suggest that the results depend also on other structural and compositional parameters within 
the macromolecular complex. Four targeting moieties seem sufficient to increase the binding forces over the monomer. At the same time, this also limits the complexity of the molecule and the potential solubility problems which could be encountered when injecting them in vivo.

In some particular cases the number of targeting peptides could be higher. For instance, liposomes or nanoparticles aimed at delivering drugs into targeted tissues can be coated with up to several hundred of targeting units. Indeed, in this case, the overall surface of the drugtransporter is important to define its degree of functionalization.

\section{CTPs first, then CPPs ?}

In this review, we have emphasized the usefulness of CPPs for improving the cellular delivery of different kinds of drugs. However, many experimental results stress that the main setback of CPPs is the absence of specific cellular delivery. Some alternative strategies, often very elegant, have been conceived with encouraging results, although they are mainly applied in very specific cases and rely on the synthesis of sometimes complex molecules. On the other hand, if these tools will reduce significantly the dose which needs to be injected, pharmaceutical companies could become interested in further developing these compounds.

We have then described some peptides that can recognize specific cell types and target these cells (CTPs). When these peptides are coupled to a drug, they specifically target a cell type, however, little is known about the efficiency of this cellular delivery. Moreover, we need also to increase the overall internalization and/or the release from the endosome of CTP-bound molecules, two features which are specific of CPPs. It would be, therefore, interesting to associate the cell specificity of CTPs with the efficient internalization and endosome release of CPPs in a chimerical molecule made with a CTP linked to a CPP. Unfortunately, several examples show that when Tat is coupled to antibodies expected to promote specific cell 
recognition there is a dramatic loss of specificity. The main problem appears to be the exposure of the CPP to the anionic cellular components of the cells. Ideally, the design of a multi-component delivery system should resemble a structure in which an exposed cellrecognition motif would first favor the concentration of the drug at the targeted cell type. At that point an efficient cell penetrating peptide attached to a payload molecule should be exposed (Figure 2). We mentioned in this review different and efficient strategies for the concentration of drugs at a specific cell type or for the local release of drug-loaded CPP. The main issue will be to combine these cell-targeting and cell-penetrating peptides into the same pharmaceutical unit and to trigger their exposure in the right place and at the right moment.

\section{Conclusions and future directions}

Unless temporally masked before being exposed at a particular site of action, the use of CPPs to mediate drug delivery into a specific cell type is far to be common in pharmacology. Such exposure can be triggered by the local $\mathrm{pH}$, the presence of specific enzymes or the mechanical release from a scavenging structure, as reviewed in the previous sections. The dispersion of most of the drug-CPP chimeras all over the body due to nonspecific interactions with ubiquitous cellular components requires the use of elevated doses of material with potential secondary effects. Despite these drawbacks, some spectacular biological effects have been reported following in vivo delivery of drugs loaded on CPPs, but the delivery of drugs into the right cell through a peptide-recognition motif has not been extensively quantified in terms of efficacy. In most of the studies, the used doses are often simply the dosages required to obtain the expected biological response, and whether such doses are very high is seldom commented in these works.

We believe that the future will lie in the development of modular units in which CPPs and CTPs will be assembled and disassembled sequentially. The first part of such a unit could be a 
polymeric structure coated with a cell-recognition peptide motif in order to concentrate the structure at the target place. Then, this structure could be dismantled by using a localized device, such as hyperthermia or ultrasounds, in order to free the internalized drug loaded-CPP in close vicinity of the target. In this way a drug could be efficiently concentrated at the tumor site and then efficiently delivered into the cancer cells (Figure 2). We expect the peptidebased delivery system of the future to be multi-unit entities, in which each unit will have a very precise function, triggered at the right moment in order to provide a more efficient and/or more tolerated therapeutic delivery strategy. In addition, peptide-based delivery vehicles remain very interesting to develop because of several advantages of peptides for drug delivery purpose (Table 2).

\section{Legend to figures:}

Figure 1: Different strategies for the "targeted" delivery mediated by CPP peptides.

A) MMP-dependent protection of the CCP: CPP is temporally neutralized by an anionic counterpart upon cleavage by the MMP present in the tumor environment. Once cleaved, the CPP detaches and vectorizes the drug into the neighboring cells (from [93]). B) PSD is an anionic molecule at $\mathrm{pH} 7.4$, leading to ionic interaction and masking of the cationic CPP. In the peritumoral environment, $\mathrm{pH}$ can decrease to 6.8 , inducing the neutralization of PSD charges, and full exposure of the CPP. The drug-loaded nanoparticle is internalized preferentially in the surrounding cells (from $[94,95])$. C) A CPP-procaspase fusion construct enters the cells. Since the HIV protease is needed to release the caspase in its active form, only HIV-infected cells will die (from [100]). D) CPP peptides are masked by long PEG 
chains. These chains are attached to the drug-loaded nanoparticle through a $\mathrm{pH}$ sensitive linker. Once in the peritumoral environment (see above), the CPP will be exposed upon cleavage of the long PEG chains (from [98]).

Figure 2: Which future for targeted delivery with CPP peptides?

A) A vesicular system containing a drug-CPP chimera coated with a cell targeting peptide (CTP) is injected in the blood stream. B) The delivery vehicle recognizes the targeted receptor and binds to it, thus concentrating the drug in a specific area. C) A device with a focused beam is focally applied at the target place to destroy the vesicular structure and to free the vesicle containing the drug-CPP chimeras. D) The drug-CPP chimeras diffuse nearby the site of concentration and are taken up preferentially by the neighboring cells.

\section{References}

[1] A.D. Frankel, and C.O. Pabo, Cellular uptake of the Tat Protein from Human immunodeficiency virus, Cell 55 (1988) 1189-1193.

[2] M. Green and P.M. Loewenstein, Autonomous functional domains of chemically synthesized human immunodeficiency virus tat trans-activator protein, Cell 55 (1988) 1179-1188.

[3] A. Joliot, C. Pernelle, B.H. Deagostini and A. Prochiantz, Antennapedia homeobox peptide regulates neural morphogenesis, Proc Natl Acad Sci U S A 88 (1991) 1864-8.

[4] D. Derossi, A.H. Joliot, G. Chassaing and A. Prochiantz, The third helix of the Antennapedia homeodomain translocates through biological membranes, J Biol Chem 269 (1994) 10444-10450.

[5] D. Derossi, S. Calvet, A. Trembleau, A. Brunissen, G. Chassaing and A. Prochiantz, Cell internalization of the third helix of the Antennapedia homeodomain is receptorindependent, J Biol Chem 271 (1996) 18188-18193. 
[6] E. Vives, P. Brodin and B. Lebleu, A truncated HIV-1 Tat protein basic domain rapidly translocates through the plasma membrane and accumulates in the cell nucleus, J Biol Chem 272 (1997) 16010-16017.

[7] P.A. Wender, J.B. Rothbard, T.C. Jessop, E.L. Kreider and B.L. Wylie, Oligocarbamate molecular transporters: design, synthesis, and biological evaluation of a new class of transporters for drug delivery, J Am Chem Soc 124 (2002) 1338213383.

[8] S. Futaki, I. Nakase, T. Suzuki, Z. Youjun and Y. Sugiura, Translocation of branchedchain arginine peptides through cell membranes: flexibility in the spatial disposition of positive charges in membrane-permeable peptides, Biochemistry 41 (2002) 79257930.

[9] D.J. Mitchell, D.T. Kim, L. Steinman, C.G. Fathman and J.B. Rothbard, Polyarginine enters cells more efficiently than other polycationic homopolymers, J Pept Res 56 (2000) 318-325.

[10] S. Futaki, Arginine-rich peptides: potential for intracellular delivery of macromolecules and the mystery of the translocation mechanisms, Int J Pharm 245 (2002) $1-7$

[11] L.R. Wright, J.B. Rothbard and P.A. Wender, Guanidinium rich Peptide transporters and drug delivery, Curr Protein Pept Sci 4 (2003) 105-124.

[12] S. Futaki, T. Suzuki, W. Ohashi, T. Yagami, S. Tanaka, K. Ueda and Y. Sugiura, Arginine-rich peptides. An abundant source of membrane-permeable peptides having potential as carriers for intracellular protein delivery, J Biol Chem 276 (2001) 58365840 .

[13] E. Vives, C. Granier, P. Prevot and B. Lebleu, Structure activity relationship study of the plasma membrane translocating potential of a short peptide from HIV-1 Tat protein, Letters In Peptide Science 4 (1997) 429-436.

[14] J.B. Rothbard, E. Kreider, C.L. VanDeusen, L. Wright, B.L. Wylie and P.A. Wender, Arginine-rich molecular transporters for drug delivery: role of backbone spacing in cellular uptake, J Med Chem 45 (2002) 3612-3618.

[15] D. Delaroche, B. Aussedat, S. Aubry, G. Chassaing, F. Burlina, G. Clodic, G. Bolbach, S. Lavielle and S. Sagan, Tracking a new cell-penetrating (W/R) nonapeptide, through an enzyme-stable mass spectrometry reporter tag, Anal Chem 79 (2007) 1932-1938. 
[16] G.P. Dietz and M. Bahr, Delivery of bioactive molecules into the cell: the Trojan horse approach, Mol Cell Neurosci 27 (2004) 85-131.

[17] E. Vives, Present and future of cell-penetrating peptide mediated delivery systems: "is the Trojan horse too wild to go only to Troy?" J Control Release 109 (2005) 77-85.

[18] J.P. Gratton, J. Yu, J.W. Griffith, R.W. Babbitt, R.S. Scotland, R. Hickey, F.J. Giordano and W.C. Sessa, Cell-permeable peptides improve cellular uptake and therapeutic gene delivery of replication-deficient viruses in cells and in vivo, Nat Med 9 (2003) 357-363.

[19] M. Jain, S.C. Chauhan, A.P. Singh, G. Venkatraman, D. Colcher and S.K. Batra, Penetratin improves tumor retention of single-chain antibodies: a novel step toward optimization of radioimmunotherapy of solid tumors, Cancer Res 65 (2005) 78407846.

[20] M.C. Morris, J. Depollier, J. Mery, F. Heitz and G. Divita, A peptide carrier for the delivery of biologically active proteins into mammalian cells, Nat Biotechnol 19 (2001) 1173-1176.

[21] S. Deshayes, M.C. Morris, G. Divita and F. Heitz, Interactions of amphipathic carrier peptides with membrane components in relation with their ability to deliver therapeutics, J Pept Sci 12 (2006) 758-765.

[22] S. Deshayes, M.C. Morris, G. Divita and F. Heitz, Interactions of amphipathic CPPs with model membranes, Biochim Biophys Acta 1758 (2006) 328-335.

[23] M.A. Munoz-Morris, F. Heitz, G. Divita and M.C. Morris, The peptide carrier Pep-1 forms biologically efficient nanoparticle complexes, Biochem Biophys Res Commun 355 (2007) 877-882.

[24] S. Deshayes, T. Plenat, P. Charnet, G. Divita, G. Molle and F. Heitz, Formation of transmembrane ionic channels of primary amphipathic cell-penetrating peptides. Consequences on the mechanism of cell penetration, Biochim Biophys Acta 1758 (2006) 1846-1851.

[25] S.T. Henriques, A. Quintas, L.A. Bagatolli, F. Homble and M.A. Castanho, Energyindependent translocation of cell-penetrating peptides occurs without formation of pores. A biophysical study with pep-1, Mol Membr Biol 24 (2007) 282-293.

[26] P.A. Wender, D.J. Mitchell, K. Pattabiraman, E.T. Pelkey, L. Steinman and J.B. Rothbard, The design, synthesis, and evaluation of molecules that enable or enhance cellular uptake: peptoid molecular transporters, Proc Natl Acad Sci U S A 97 (2000) 13003-13008. 
[27] M. Pooga, U. Soomets, M. Hallbrink, A. Valkna, K. Saar, K. Rezaei, U. Kahl, J.X. Hao, X.J. Xu, H.Z. Wiesenfeld, T. Hokfelt, T. Bartfai and U. Langel, Cell penetrating PNA constructs regulate galanin receptor levels and modify pain transmission in vivo, Nat Biotechnol 16 (1998) 857-861.

[28] M.C. Morris, P. Vidal, L. Chaloin, F. Heitz and G. Divita, A new peptide vector for efficient delivery of oligonucleotides into mammalian cells, Nucleic Acids Res 25 (1997) 2730-2736.

[29] P.E. Thoren, D. Persson, E.K. Esbjorner, M. Goksor, P. Lincoln and B. Norden, Membrane binding and translocation of cell-penetrating peptides, Biochemistry 43 (2004) 3471-3489.

[30] P.E. Thoren, D. Persson, P. Lincoln and B. Norden, Membrane destabilizing properties of cell-penetrating peptides, Biophys Chem 114 (2005) 169-179.

[31] V.P. Torchilin, R. Rammohan, V. Weissig and T.S. Levchenko, TAT peptide on the surface of liposomes affords their efficient intracellular delivery even at low temperature and in the presence of metabolic inhibitors, Proc Natl Acad Sci U S A 98 (2001) 8786-8791.

[32] M. Lewin, N. Carlesso, C.H. Tung, X.W. Tang, D. Cory, D.T. Scadden and R. Weissleder, Tat peptide-derivatized magnetic nanoparticles allow in vivo tracking and recovery of progenitor cells, Nat Biotechnol 18 (2000) 410-414.

[33] J.P. Richard, K. Melikov, E. Vives, C. Ramos, B. Verbeure, M.J. Gait, L.V. Chernomordik and B. Lebleu, Cell-penetrating peptides. A reevaluation of the mechanism of cellular uptake, J Biol Chem 278 (2003) 585-590.

[34] M. Lundberg and M. Johansson, Positively charged DNA-binding proteins cause apparent cell membrane translocation, Biochem Biophys Res Commun 291 (2002) 367-371.

[35] M. Lundberg, S. Wikstrom and M. Johansson, Cell surface adherence and endocytosis of protein transduction domains, Mol Ther 8 (2003) 143-150.

[36] S. Futaki, Membrane-permeable arginine-rich peptides and the translocation mechanisms, Adv Drug Deliv Rev 57 (2005) 547-558.

[37] S.W. Jones, R. Christison, K. Bundell, C.J. Voyce, S.M. Brockbank, P. Newham and M.A. Lindsay, Characterisation of cell-penetrating peptide-mediated peptide delivery, Br J Pharmacol 145 (2005) 1093-1102. 
[38] F. Duchardt, M. Fotin-Mleczek, H. Schwarz, R. Fischer and R. Brock, A comprehensive model for the cellular uptake of cationic cell-penetrating peptides, Traffic 8 (2007) 848-866.

[39] E. Vives, J.P. Richard, C. Rispal and B. Lebleu, TAT Peptide Internalization: Seeking the Mechanism of Entry, Curr Protein Pept Sci 4 (2003) 125-132.

[40] H. Brooks, B. Lebleu and E. Vives, Tat peptide-mediated cellular delivery: back to basics, Adv Drug Deliv Rev 57 (2005) 559-577.

[41] I. Nakase, A. Tadokoro, N. Kawabata, T. Takeuchi, H. Katoh, K. Hiramoto, M. Negishi, M. Nomizu, Y. Sugiura and S. Futaki, Interaction of arginine-rich peptides with membrane-associated proteoglycans is crucial for induction of actin organization and macropinocytosis, Biochemistry 46 (2007) 492-501.

[42] A. Fittipaldi, A. Ferrari, M. Zoppe, C. Arcangeli, V. Pellegrini, F. Beltram and M. Giacca, Cell membrane lipid rafts mediate caveolar endocytosis of HIV-1 tat fusion proteins, J Biol Chem (2003) 34141 - 34149.

[43] I.M. Kaplan, J.S. Wadia and S.F. Dowdy, Cationic TAT peptide transduction domain enters cells by macropinocytosis, J Control Release 102 (2005) 247-253.

[44] I. Nakase, M. Niwa, T. Takeuchi, K. Sonomura, N. Kawabata, Y. Koike, M. Takehashi, S. Tanaka, K. Ueda, J.C. Simpson, A.T. Jones, Y. Sugiura and S. Futaki, Cellular uptake of arginine-rich peptides: roles for macropinocytosis and actin rearrangement, Mol Ther 10 (2004) 1011-1022.

[45] J.P. Richard, K. Melikov, H. Brooks, P. Prevot, B. Lebleu and L.V. Chernomordik, Cellular uptake of unconjugated TAT peptide involves clathrin-dependent endocytosis and heparan sulfate receptors, J Biol Chem 280 (2005) 15300-15306.

[46] R.E. Vandenbroucke, S.C. De Smedt, J. Demeester and N.N. Sanders, Cellular entry pathway and gene transfer capacity of TAT-modified lipoplexes, Biochim Biophys Acta 1768 (2007) 571-579.

[47] R. Fischer, K. Kohler, M. Fotin-Mleczek and R. Brock, A Stepwise Dissection of the Intracellular Fate of Cationic Cell-penetrating Peptides, J Biol Chem 279 (2004) $12625-12635$.

[48] E. Dupont, A. Prochiantz and A. Joliot, Identification of a signal peptide for unconventional secretion, J Biol Chem 282 (2007) 8994-9000.

[49] G. Tunnemann, R.M. Martin, S. Haupt, C. Patsch, F. Edenhofer and M.C. Cardoso, Cargo-dependent mode of uptake and bioavailability of TAT-containing proteins and peptides in living cells, Faseb J 20 (2006) 1775-1784. 
[50] H.D. Herce and A.E. Garcia, Molecular dynamics simulations suggest a mechanism for translocation of the HIV-1 TAT peptide across lipid membranes, Proc Natl Acad Sci U S A 104 (2007) 20805-20810.

[51] M. Rusnati, C. Urbinati, A. Caputo, L. Possati, H. Lortat-Jacob, M. Giacca, D. Ribatti and M. Presta, Pentosan polysulfate as an inhibitor of extracellular HIV-1 Tat, J Biol Chem 276 (2001) 22420-22425.

[52] M. Tyagi, M. Rusnati, M. Presta and M. Giacca, Internalization of HIV-1 tat requires cell surface heparan sulfate proteoglycans, J Biol Chem 276 (2001) 3254-3261.

[53] T. Suzuki, S. Futaki, M. Niwa, S. Tanaka, K. Ueda and Y. Sugiura, Possible existence of common internalization mechanisms among arginine- rich peptides, J Biol Chem 277 (2002) 2437-2443.

[54] C. Marty, C. Meylan, H. Schott, K. Ballmer-Hofer and R.A. Schwendener, Enhanced heparan sulfate proteoglycan-mediated uptake of cell-penetrating peptide-modified liposomes, Cell Mol Life Sci 61 (2004) 1785-1794.

[55] S. Kameyama, M. Horie, T. Kikuchi, T. Omura, A. Tadokoro, T. Takeuchi, I. Nakase, Y. Sugiura and S. Futaki, Acid wash in determining cellular uptake of Fab/cellpermeating peptide conjugates, Biopolymers 88 (2007) 98-107.

[56] S. El-Andaloussi, P. Jarver, H.J. Johansson and U. Langel, Cargo dependent cytotoxicity and delivery efficacy of cell-penetrating peptides: a comparative study, Biochem J 15 (2007) 285-292.

[57] N.J. Caron, S.P. Quenneville and J.P. Tremblay, Endosome disruption enhances the functional nuclear delivery of Tat-fusion proteins, Biochem Biophys Res Commun 319 (2004) 12-20.

[58] S. Abes, D. Williams, P. Prevot, A. Thierry, M.J. Gait and B. Lebleu, Endosome trapping limits the efficiency of splicing correction by PNA-oligolysine conjugates, $\mathrm{J}$ Control Release 110 (2006) 595-604.

[59] J.S. Wadia, R.V. Stan and S.F. Dowdy, Transducible TAT-HA fusogenic peptide enhances escape of TAT-fusion proteins after lipid raft macropinocytosis, Nat Med 10 (2004) 310-315.

[60] T. Shiraishi and P.E. Nielsen, Photochemically enhanced cellular delivery of cell penetrating peptide-PNA conjugates, FEBS Lett 580 (2006) 1451-1456.

[61] Y.J. Seo, H.S. Jeong, E.K. Bang, G.T. Hwang, J.H. Jung, S.K. Jang and B.H. Kim, Cholesterol-linked fluorescent molecular beacons with enhanced cell permeability, Bioconjug Chem 17 (2006) 1151-1155. 
[62] T. LeDoan, F. Etore, J.P. Tenu, Y. Letourneux and S. Agrawal, Cell binding, uptake and cytosolic partition of HIV anti-gag phosphodiester oligonucleotides 3'-linked to cholesterol derivatives in macrophages, Bioorg Med Chem 7 (1999) 2263-2269.

[63] I.A. Khalil, S. Futaki, M. Niwa, Y. Baba, N. Kaji, H. Kamiya and H. Harashima, Mechanism of improved gene transfer by the N-terminal stearylation of octaarginine: enhanced cellular association by hydrophobic core formation, Gene Ther 11 (2004) 636-644.

[64] S. Pujals, J. Fernandez-Carneado, M.J. Kogan, J. Martinez, F. Cavelier and E. Giralt, Replacement of a proline with silaproline causes a 20 -fold increase in the cellular uptake of a Pro-rich peptide, J Am Chem Soc 128 (2006) 8479-8483.

[65] S.R. Schwarze, A. Ho, A. Vocero-Akbani and S.F. Dowdy, In vivo protein transduction: delivery of a biologically active protein into the mouse, Science 285 (1999) 1569-1572.

[66] G. Cao, W. Pei, H. Ge, Q. Liang, Y. Luo, F.R. Sharp, A. Lu, R. Ran, S.H. Graham and J. Chen, In Vivo Delivery of a Bcl-xL Fusion Protein Containing the TAT Protein Transduction Domain Protects against Ischemic Brain Injury and Neuronal Apoptosis, J Neurosci 22 (2002) 5423-5431.

[67] C. Rousselle, P. Clair, J.M. Lefauconnier, M. Kaczorek, J.M. Scherrmann and J. Temsamani, New advances in the transport of doxorubicin through the blood-brain barrier by a peptide vector-mediated strategy, Mol Pharmacol 57 (2000) 679-686.

[68] U. Niesner, C. Halin, L. Lozzi, M. Gunthert, P. Neri, H. Wunderli-Allenspach, L. Zardi and D. Neri, Quantitation of the tumor-targeting properties of antibody fragments conjugated to cell-permeating HIV-1 TAT peptides, Bioconjug Chem 13 (2002) 729-736.

[69] E. Vives, Cellular uptake of the Tat peptide: an endocytosis mechanism following ionic interactions, J Mol Recognit 16 (2003) 265-271.

[70] D.C. Anderson, E. Nichols, R. Manger, D. Woodle, M. Barry and A.R. Fritzberg, Tumor cell retention of antibody Fab fragments is enhanced by an attached HIV TAT protein-derived peptide, Biochem Biophys Res Commun 194 (1993) 876-884.

[71] M. Hu, P. Chen, J. Wang, D.A. Scollard, K.A. Vallis and R.M. Reilly, (123)I-labeled HIV-1 tat peptide radioimmunoconjugates are imported into the nucleus of human breast cancer cells and functionally interact in vitro and in vivo with the cyclindependent kinase inhibitor, p21(WAF-1/Cip-1), Eur J Nucl Med Mol Imaging 34 (2006) 368-377. 
[72] S. Stein, A. Weiss, K. Adermann, P. Lazarovici, J. Hochman and H. Wellhoner, A disulfide conjugate between anti-tetanus antibodies and HIV (37- 72)Tat neutralizes tetanus toxin inside chromaffin cells, FEBS Lett 458 (1999) 383-386.

[73] M. Hallbrink, A. Floren, A. Elmquist, M. Pooga, T. Bartfai and U. Langel, Cargo delivery kinetics of cell-penetrating peptides, Biochim Biophys Acta 1515 (2001) 101109.

[74] T. Subramanian, M. Kuppuswamy, L. Venkatish, A. Srinivasan, and G. Chinnadurai, Functional substitution of the basic domain of the HIV-1 Tat with the basic domain of the functionally heterologous REV., Virology 176 (1990) 178-183.

[75] H.M. Moulton, M.H. Nelson, S.A. Hatlevig, M.T. Reddy and P.L. Iversen, Cellular uptake of antisense morpholino oligomers conjugated to arginine-rich peptides, Bioconjug Chem 15 (2004) 290-299.

[76] S. Kameyama, M. Horie, T. Kikuchi, T. Omura, T. Takeuchi, I. Nakase, Y. Sugiura and S. Futaki, Effects of cell-permeating peptide binding on the distribution of 125Ilabeled Fab fragment in rats, Bioconjug Chem 17 (2006) 597-602.

[77] A. El-Aneed, An overview of current delivery systems in cancer gene therapy, J Control Release 94 (2004) 1-14.

[78] J.E. King, E.A. Eugenin, C.M. Buckner and J.W. Berman, HIV tat and neurotoxicity, Microbes Infect 8 (2006) 1347-1357.

[79] B.S. Weeks, D.M. Lieberman, B. Johnson, E. Roque, M. Green, P. Loewenstein, E.H. Oldfield and H.K. Kleinman, Neurotoxicity of the human immunodeficiency virus type 1 tat transactivator to PC12 cells requires the Tat amino acid 49-58 basic domain, J Neurosci Res 42 (1995) 34-40.

[80] J.M. Sabatier, E. Vives, K. Mabrouk, A. Benjouad, H. Rochat, A. Duval, B. Hue and E. Bahraoui, Evidence for neurotoxic activity of tat from human immunodeficiency virus type 1, J Virol 65 (1991) 961-967.

[81] A. Toro, M. Paiva, C. Ackerley and E. Grunebaum, Intracellular delivery of purine nucleoside phosphorylase (PNP) fused to protein transduction domain corrects PNP deficiency in vitro, Cell Immunol, 240 (2006) 107-115.

[82] T. Sugita, T. Yoshikawa, Y. Mukai, N. Yamanada, S. Imai, K. Nagano, Y. Yoshida, H. Shibata, Y. Yoshioka, S. Nakagawa, H. Kamada, S.I. Tsunoda and Y. Tsutsumi, Comparative study on transduction and toxicity of protein transduction domains, $\mathrm{Br} \mathrm{J}$ Pharmacol (2008) advance online publication. 
[83] W.J. Kim, L.V. Christensen, S. Jo, J.W. Yockman, J.H. Jeong, Y.H. Kim and S.W. Kim, Cholesteryl oligoarginine delivering vascular endothelial growth factor siRNA effectively inhibits tumor growth in colon adenocarcinoma, Mol Ther 14 (2006) 343350.

[84] R. Akkarawongsa, A.E. Cullinan, A. Zinkel, J. Clarin and C.R. Brandt, Corneal toxicity of cell-penetrating peptides that inhibit Herpes simplex virus entry, J Ocul Pharmacol Ther 22 (2006) 279-289.

[85] Y.J. Park, L.C. Chang, J.F. Liang, C. Moon, C.P. Chung and V.C. Yang, Nontoxic membrane translocation peptide from protamine, low molecular weight protamine (LMWP), for enhanced intracellular protein delivery: in vitro and in vivo study, Faseb J 19 (2005) 1555-1557.

[86] A.K. Cardozo, V. Buchillier, M. Mathieu, J. Chen, F. Ortis, L. Ladriere, N. AllamanPillet, O. Poirot, S. Kellenberger, J.S. Beckmann, D.L. Eizirik, C. Bonny and F. Maurer, Cell-permeable peptides induce dose- and length-dependent cytotoxic effects, Biochim Biophys Acta 1768 (2007) 2222-22234.

[87] J.B. Rothbard, S. Garlington, Q. Lin, T. Kirschberg, E. Kreider, P.L. McGrane, P.A. Wender and P.A. Khavari, Conjugation of arginine oligomers to cyclosporin A facilitates topical delivery and inhibition of inflammation, Nat Med 6 (2000) 12531257.

[88] D.F. Schorderet, V. Manzi, K. Canola, C. Bonny, Y. Arsenijevic, F.L. Munier and F. Maurer, D-TAT transporter as an ocular peptide delivery system, Clin Experiment Ophthalmol 33 (2005) 628-635.

[89] K. Inagaki, H.S. Hahn, G.W. Dorn, 2nd and D. Mochly-Rosen, Additive protection of the ischemic heart ex vivo by combined treatment with delta-protein kinase $\mathrm{C}$ inhibitor and epsilon-protein kinase C activator, Circulation 108 (2003) 869-875.

[90] S.A. Moschos, S.W. Jones, M.M. Perry, A.E. Williams, J.S. Erjefalt, J.J. Turner, P.J. Barnes, B.S. Sproat, M.J. Gait and M.A. Lindsay, Lung Delivery Studies Using siRNA Conjugated to TAT(48-60) and Penetratin Reveal Peptide Induced Reduction in Gene Expression and Induction of Innate Immunity, Bioconjug Chem 18 (2007) 1450-1459.

[91] J.S. Patton and P.R. Byron, Inhaling medicines: delivering drugs to the body through the lungs, Nat Rev Drug Discov 6 (2007) 67-74.

[92] S. Kameyama, R. Okada, T. Kikuchi, T. Omura, I. Nakase, T. Takeuchi, Y. Sugiura and S. Futaki, Distribution of immunoglobulin Fab fragment conjugated with HIV-1 
REV peptide following intravenous administration in rats, Mol Pharm 3 (2006) 174180.

[93] T. Jiang, E.S. Olson, Q.T. Nguyen, M. Roy, P.A. Jennings and R.Y. Tsien, Tumor imaging by means of proteolytic activation of cell-penetrating peptides, Proc Natl Acad Sci U S A 101 (2004) 17867-17872.

[94] V.A. Sethuraman and Y.H. Bae, TAT peptide-based micelle system for potential active targeting of anti-cancer agents to acidic solid tumors, J Control Release 118 (2007) 216-224.

[95] V.A. Sethuraman, K. Na and Y.H. Bae, pH-responsive sulfonamide/PEI system for tumor specific gene delivery: an in vitro study, Biomacromolecules 7 (2006) 64-70.

[96] M. Stubbs, P.M. McSheehy, J.R. Griffiths and C.L. Bashford, Causes and consequences of tumour acidity and implications for treatment, Mol Med Today 6 (2000) 15-19.

[97] R.A. Gatenby, E.T. Gawlinski, A.F. Gmitro, B. Kaylor and R.J. Gillies, Acidmediated tumor invasion: a multidisciplinary study, Cancer Res 66 (2006) 5216-5223.

[98] A.A. Kale and V.P. Torchilin, Enhanced transfection of tumor cells in vivo using "Smart" pH-sensitive TAT-modified pegylated liposomes, J Drug Target 15 (2007) 538-545.

[99] E. Wagner, C. Plank, K. Zatloukal, M. Cotten and M.L. Birnstiel, Influenza virus hemagglutinin HA-2 N-terminal fusogenic peptides augment gene transfer by transferrin-polylysine-DNA complexes: toward a synthetic virus-like gene-transfer vehicle, Proc Natl Acad Sci U S A 89 (1992) 7934-7938.

[100] A.M. Vocero-Akbani, N.V. Heyden, N.A. Lissy, L. Ratner and S.F. Dowdy, Killing HIV-infected cells by transduction with an HIV protease- activated caspase-3 protein [see comments], Nat Med 5 (1999) 29-33.

[101] E.L. Snyder, B.R. Meade and S.F. Dowdy, Anti-cancer protein transduction strategies: reconstitution of p27 tumor suppressor function, J Control Release 91 (2003) 45-51.

[102] C. Garcia-Echeverria, P. Chene, M.J. Blommers and P. Furet, Discovery of potent antagonists of the interaction between human double minute 2 and tumor suppressor p53, J Med Chem 43 (2000) 3205-3208.

[103] C. Garcia-Echeverria, P. Furet and P. Chene, Coupling of the antennapedia third helix to a potent antagonist of the $\mathrm{p} 53 / \mathrm{hdm} 2$ protein-protein interaction, Bioorg Med Chem Lett 11 (2001) 2161-2164. 
[104] L. Chen and S.D. Harrison, Cell-penetrating peptides in drug development: enabling intracellular targets, Biochem Soc Trans 35 (2007) 821-825.

[105] G.L. Bidwell, 3rd, I. Fokt, W. Priebe and D. Raucher, Development of elastin-like polypeptide for thermally targeted delivery of doxorubicin, Biochem Pharmacol 73 (2007) 620-631.

[106] I. Massodi and D. Raucher, A thermally responsive Tat-elastin-like polypeptide fusion protein induces membrane leakage, apoptosis, and cell death in human breast cancer cells, J Drug Target 15 (2007) 611-622.

[107] S. Dromi, V. Frenkel, A. Luk, B. Traughber, M. Angstadt, M. Bur, J. Poff, J. Xie, S.K. Libutti, K.C. Li and B.J. Wood, Pulsed-high intensity focused ultrasound and low temperature-sensitive liposomes for enhanced targeted drug delivery and antitumor effect, Clin Cancer Res 13 (2007) 2722-2727.

[108] R. Duncan, H.C. Cable, J.B. Lloyd, P. Rejmanova and J. Kopecek, Degradation of side-chains of N-(2-hydroxypropyl)methacrylamide copolymers by lysosomal thiolproteinases, Biosci Rep 2 (1982) 1041-1046.

[109] C.J. Gannon, P. Cherukuri, B.I. Yakobson, L. Cognet, J.S. Kanzius, C. Kittrell, R.B. Weisman, M. Pasquali, H.K. Schmidt, R.E. Smalley and S.A. Curley, Carbon nanotube-enhanced thermal destruction of cancer cells in a noninvasive radiofrequency field, Cancer 15 (2007) 2654-2665.

[110] P. Asuri, S.S. Bale, R.C. Pangule, D.A. Shah, R.S. Kane and J.S. Dordick, Structure, Function, and Stability of Enzymes Covalently Attached to Single-Walled Carbon Nanotubes, Langmuir 20 (2007) 12318-12321.

[111] R.K. Schlicher, H. Radhakrishna, T.P. Tolentino, R.P. Apkarian, V. Zarnitsyn and M.R. Prausnitz, Mechanism of intracellular delivery by acoustic cavitation, Ultrasound Med Biol 32 (2006) 915-924.

[112] K. Iwanaga, K. Tominaga, K. Yamamoto, M. Habu, H. Maeda, S. Akifusa, T. Tsujisawa, T. Okinaga, J. Fukuda and T. Nishihara, Local delivery system of cytotoxic agents to tumors by focused sonoporation, Cancer Gene Ther 14 (2007) 354-363.

[113] S. Sonoda, K. Tachibana, E. Uchino, T. Yamashita, K. Sakoda, K.H. Sonoda, T. Hisatomi, Y. Izumi and T. Sakamoto, Inhibition of Melanoma by UltrasoundMicrobubble-Aided Drug Delivery Suggests Membrane Permeabilization, Cancer Biol Ther 6 (2007) 1276-1283.

[114] Z.G. Gao, H.D. Fain and N. Rapoport, Controlled and targeted tumor chemotherapy by micellar-encapsulated drug and ultrasound, J Control Release 102 (2005) 203-222. 
[115] Z. Gao, H.D. Fain and N. Rapoport, Ultrasound-enhanced tumor targeting of polymeric micellar drug carriers, Mol Pharm 1 (2004) 317-330.

[116] A.J. Beer, R. Haubner, M. Sarbia, M. Goebel, S. Luderschmidt, A.L. Grosu, O. Schnell, M. Niemeyer, H. Kessler, H.J. Wester, W.A. Weber and M. Schwaiger, Positron emission tomography using [18F]Galacto-RGD identifies the level of integrin alpha(v)beta3 expression in man, Clin Cancer Res 12 (2006) 3942-3949.

[117] R. Pasqualini, E. Koivunen and E. Ruoslahti, Alpha v integrins as receptors for tumor targeting by circulating ligands, Nat Biotechnol 15 (1997) 542-546.

[118] D. Heckmann and H. Kessler, Design and chemical synthesis of integrin ligands, Methods Enzymol 426 (2007) 463-503.

[119] K.R. Gehlsen, W.S. Argraves, M.D. Pierschbacher and E. Ruoslahti, Inhibition of in vitro tumor cell invasion by Arg-Gly-Asp-containing synthetic peptides, J Cell Biol 106 (1988) 925-930.

[120] R. Abou-Jawde, T. Choueiri, C. Alemany and T. Mekhail, An overview of targeted treatments in cancer, Clin Ther 25 (2003) 2121-2137.

[121] T. Ekida, C. Nishimura, S. Masuda, S. Itoh, I. Shimada and Y. Arata, A receptorbinding peptide from human interleukin-6: isolation and a proton nuclear magnetic resonance study, Biochem Biophys Res Commun 189 (1992) 211-220.

[122] M.A. VanVolkenburg, N.D. Griggs, M.A. Jarpe, J.L. Pace, S.W. Russell and H.M. Johnson, Binding site on the murine IFN-gamma receptor for IFN-gamma has been identified using the synthetic peptide approach, J Immunol 151 (1993) 6206-6213.

[123] X.F. Wang, M. Birringer, L.F. Dong, P. Veprek, P. Low, E. Swettenham, M. Stantic, L.H. Yuan, R. Zobalova, K. Wu, M. Ledvina, S.J. Ralph and J. Neuzil, A peptide conjugate of vitamin E succinate targets breast cancer cells with high ErbB2 expression, Cancer Res 67 (2007) 3337-3344.

[124] G.Y. Perret, A. Starzec, N. Hauet, J. Vergote, M. Le Pecheur, R. Vassy, G. Leger, K.A. Verbeke, G. Bormans, P. Nicolas, A.M. Verbruggen and J.L. Moretti, In vitro evaluation and biodistribution of a 99mTc-labeled anti-VEGF peptide targeting neuropilin-1, Nucl Med Biol 31 (2004) 575-581.

[125] A. Starzec, R. Vassy, A. Martin, M. Lecouvey, M. Di Benedetto, M. Crepin and G.Y. Perret, Antiangiogenic and antitumor activities of peptide inhibiting the vascular endothelial growth factor binding to neuropilin-1, Life Sci 79 (2006) 2370-2381. 
[126] C. Wiesmann, H.W. Christinger, A.G. Cochran, B.C. Cunningham, W.J. Fairbrother, C.J. Keenan, G. Meng and A.M. de Vos, Crystal structure of the complex between VEGF and a receptor-blocking peptide, Biochemistry 37 (1998) 17765-17772.

[127] J.K. Scott and G.P. Smith, Searching for peptide ligands with an epitope library, Science 249 (1990) 386-390.

[128] J.A. Este, Virus entry as a target for anti-HIV intervention, Curr Med Chem 10 (2003) 1617-1632.

[129] H. Depraetere, A. Viaene, S. Deroo, S. Vauterin and H. Deckmyn, Identification of peptides, selected by phage display technology, that inhibit von Willebrand factor binding to collagen, Blood 92 (1998) 4207-4211.

[130] W. Arap, R. Pasqualini and E. Ruoslahti, Cancer treatment by targeted drug delivery to tumor vasculature in a mouse model, Science 279 (1998) 377-380.

[131] S.E. Salmon, R.H. Liu-Stevens, Y. Zhao, M. Lebl, V. Krchnak, K. Wertman, N. Sepetov and K.S. Lam, High-volume cellular screening for anticancer agents with combinatorial chemical libraries: a new methodology, Mol Divers 2 (1996) 57-63.

[132] O.H. Aina, T.C. Sroka, M.L. Chen and K.S. Lam, Therapeutic cancer targeting peptides, Biopolymers 66 (2002) 184-199.

[133] O.H. Aina, R. Liu, J.L. Sutcliffe, J. Marik, C.X. Pan and K.S. Lam, From Combinatorial Chemistry to Cancer-Targeting Peptides, Mol Pharm 4 (2007) 631-651.

[134] L. Peng, R. Liu, J. Marik, X. Wang, Y. Takada and K.S. Lam, Combinatorial chemistry identifies high-affinity peptidomimetics against alpha4betal integrin for in vivo tumor imaging, Nat Chem Biol 2 (2006) 381-389.

[135] J.A. Varner and D.A. Cheresh, Tumor angiogenesis and the role of vascular cell integrin alphavbeta3, Important Adv Oncol (1996) 69-87.

[136] M.A. Dechantsreiter, E. Planker, B. Matha, E. Lohof, G. Holzemann, A. Jonczyk, S.L. Goodman and H. Kessler, N-Methylated cyclic RGD peptides as highly active and selective alpha(V)beta(3) integrin antagonists, J Med Chem 42 (1999) 3033-3040.

[137] R. Haubner, D. Finsinger and H. Kessler, Stereoisomeric peptide libraries and peptidomimetics for designing selective inhibitors of the avb3 integrin for a new cancer therapy, Angew. Chem. Int. Ed. Eng 36 (1997) 1374-1389.

[138] S.J. Bogdanowich-Knipp, D.S. Jois and T.J. Siahaan, The effect of conformation on the solution stability of linear vs. cyclic RGD peptides, J Pept Res 53 (1999) 523-529.

[139] C.E. Peishoff, F.E. Ali, J.W. Bean, R. Calvo, C.A. D'Ambrosio, D.S. Eggleston, S.M. Hwang, T.P. Kline, P.F. Koster, A. Nichols and et al., Investigation of conformational 
specificity at GPIIb/IIIa: evaluation of conformationally constrained RGD peptides, J Med Chem 35 (1992) 3962-3969.

[140] S.L. Hart, L. Collins, K. Gustafsson and J.W. Fabre, Integrin-mediated transfection with peptides containing arginine- glycine-aspartic acid domains, Gene Ther 4 (1997) 1225-1230.

[141] F.M. de Groot, H.J. Broxterman, H.P. Adams, A. van Vliet, G.I. Tesser, Y.W. Elderkamp, A.J. Schraa, R.J. Kok, G. Molema, H.M. Pinedo and H.W. Scheeren, Design, synthesis, and biological evaluation of a dual tumor-specific motive containing integrin-targeted plasmin-cleavable doxorubicin prodrug, Mol Cancer Ther 1 (2002) 901-911.

[142] M. Pfaff, K. Tangemann, B. Muller, M. Gurrath, G. Muller, H. Kessler, R. Timpl and J. Engel, Selective recognition of cyclic RGD peptides of NMR defined conformation by alpha IIb beta 3, alpha V beta 3, and alpha 5 beta 1 integrins, J Biol Chem 269 (1994) 20233-20238.

[143] L.D. D'Andrea, A. Del Gatto, C. Pedone and E. Benedetti, Peptide-based molecules in angiogenesis, Chem Biol Drug Des 67 (2006) 115-126.

[144] P.S. Portoghese, G. Ronsisvalle, D.L. Larson, C.B. Yim, L.M. Sayre and A.E. Takemori, Opioid agonist and antagonist bivalent ligands as receptor probes, Life Sci 31 (1982) 1283-1286.

[145] Y. Ye, S. Bloch, B. Xu and S. Achilefu, Design, synthesis, and evaluation of near infrared fluorescent multimeric RGD peptides for targeting tumors, J Med Chem 49 (2006) 2268-2275.

[146] J.P. Xiong, T. Stehle, B. Diefenbach, R. Zhang, R. Dunker, D.L. Scott, A. Joachimiak, S.L. Goodman and M.A. Arnaout, Crystal structure of the extracellular segment of integrin alpha Vbeta3, Science 294 (2001) 339-345.

[147] I. Dijkgraaf, J.A. Kruijtzer, S. Liu, A.C. Soede, W.J. Oyen, F.H. Corstens, R.M. Liskamp and O.C. Boerman, Improved targeting of the alpha(v)beta (3) integrin by multimerisation of RGD peptides, Eur J Nucl Med Mol Imaging 34 (2007) 267-273.

[148] I. Dijkgraaf, S. Liu, J.A. Kruijtzer, A.C. Soede, W.J. Oyen, R.M. Liskamp, F.H. Corstens and O.C. Boerman, Effects of linker variation on the in vitro and in vivo characteristics of an 111In-labeled RGD peptide, Nucl Med Biol 34 (2007) 29-35.

[149] X. Chen, M. Tohme, R. Park, Y. Hou, J.R. Bading and P.S. Conti, Micro-PET imaging of alphavbeta3-integrin expression with 18F-labeled dimeric RGD peptide, Mol Imaging 3 (2004) 96-104. 
[150] T.D. Harris, E. Cheesman, A.R. Harris, R. Sachleben, D.S. Edwards, S. Liu, J. Bartis, C. Ellars, D. Onthank, P. Yalamanchili, S. Heminway, P. Silva, S. Robinson, J. Lazewatsky, M. Rajopadhye and J. Barrett, Radiolabeled divalent peptidomimetic vitronectin receptor antagonists as potential tumor radiotherapeutic and imaging agents, Bioconjug Chem 18 (2007) 1266-1279.

[151] H.L. Handl, R. Sankaranarayanan, J.S. Josan, J. Vagner, E.A. Mash, R.J. Gillies and V.J. Hruby, Synthesis and evaluation of bivalent NDP-alpha-MSH(7) peptide ligands for binding to the human melanocortin receptor 4 (hMC4R), Bioconjug Chem 18 (2007) 1101-1119.

[152] M.L. Janssen, W.J. Oyen, I. Dijkgraaf, L.F. Massuger, C. Frielink, D.S. Edwards, M. Rajopadhye, H. Boonstra, F.H. Corstens and O.C. Boerman, Tumor targeting with radiolabeled alpha(v)beta(3) integrin binding peptides in a nude mouse model, Cancer Res 62 (2002) 6146-6151.

[153] G. Thumshirn, U. Hersel, S.L. Goodman and H. Kessler, Multimeric cyclic RGD peptides as potential tools for tumor targeting: solid-phase peptide synthesis and chemoselective oxime ligation, Chemistry 9 (2003) 2717-2725.

[154] D. Boturyn, J.L. Coll, E. Garanger, M.C. Favrot and P. Dumy, Template assembled cyclopeptides as multimeric system for integrin targeting and endocytosis, J Am Chem Soc 126 (2004) 5730-5739.

[155] Z.H. Jin, V. Josserand, J. Razkin, E. Garanger, D. Boturyn, M.C. Favrot, P. Dumy and J.L. Coll, Noninvasive optical imaging of ovarian metastases using Cy5-labeled RAFT-c(-RGDfK-)4, Mol Imaging 5 (2006) 188-197.

[156] Z.H. Jin, V. Josserand, S. Foillard, D. Boturyn, P. Dumy, M.C. Favrot and J.L. Coll, In vivo optical imaging of integrin alphaV-beta3 in mice using multivalent or monovalent cRGD targeting vectors, Mol Cancer 6 (2007) 41-50.

[157] D.N. Posnett, H. McGrath and J.P. Tam, A novel method for producing anti-peptide antibodies. Production of site-specific antibodies to the $\mathrm{T}$ cell antigen receptor betachain, J Biol Chem 263 (1988) 1719-1725.

[158] D. Lossner, H. Kessler, G. Thumshirn, C. Dahmen, B. Wiltschi, M. Tanaka, W. Knoll, E.K. Sinner and U. Reuning, Binding of small mono- and oligomeric integrin ligands to membrane-embedded integrins monitored by surface plasmon-enhanced fluorescence spectroscopy, Anal Chem 78 (2006) 4524-4533. 